\title{
Caracterização e uso de xisto para adsorção de chumbo (II) em solução
}

\section{(Characterization and use of retorted shale for adsorption of lead (II) in solution)}

\author{
P. M. Pimentel ${ }^{1}$, C. N. Silva Jr. ${ }^{1}$, D. M. A. Melo ${ }^{1}$, M. A. F. Melo ${ }^{1}$, G. Maldonado ${ }^{2}$, D. M. Henrique ${ }^{1}$ \\ ${ }^{1}$ Laboratório de Análise Térmica e Materiais, Departamento de Química, \\ Universidade Federal do Rio Grande do Norte \\ C.P. 1662, Natal, RN, 59078-970 \\ ${ }^{2}$ Universidade Federal do Rio de Janeiro e CENPES
}

\begin{abstract}
Resumo
Existe um grande interesse no uso de materiais de baixo custo para remoção de metais pesados em águas residuais. Novas técnicas de processamento e adsorventes incluindo argilas, resinas sintéticas, turfa e quitosana tem sido estudados objetivando substituir o carvão ativado. No presente trabalho, xisto retortado (XR), um rejeito sólido da transformação térmica do xisto oleígeno, foi caracterizado com o objetivo de utilizá-lo como adsorventes para remoção de metais pesados. O aproveitamento desse rejeito é de grande interesse, uma vez que o Brasil possui a segunda maior reserva mundial de xisto oleígeno. Os rejeitos foram caracterizados por diferentes técnicas de caracterização, incluindo tamanho de partícula, análise termogravimétrica, fluorescência de raios X, espectroscopia na região do infravermelho, difração de raios X, e microscopia eletrônica de varredura-EDS. As características dos pós foram adequadas

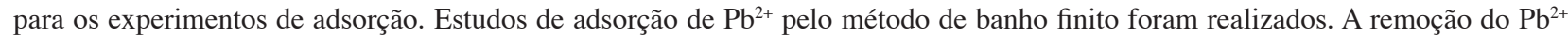
foi superior a $85 \%$.
\end{abstract}

Palavras-chave: xisto retortado, adsorsão, argilas.

\begin{abstract}
There has been a growing interest in the use of cost-effective materials to remove heavy metals from wastewater. New processing techniques and adsorbents including natural clays, synthetic resins, peat and chitosan have been studied aiming at replacing activated coal. In the present investigation, retorted shale, a solid residue of the thermal transformation of oil shale, was characterized with the objective of preparing heavy metals adsorbents. In addition to the direct environmental benefits from the technology to wastewater, Brazil has the second world reserve of oil shale. The fine residue was fully characterized by different techniques including particle size determination, thermogravimetric analyses, BET, FTIR, X-ray diffraction, and SEM/EDS. The characteristics of the powder were appropriate for adsorption. Batch adsorption studies in $\mathrm{Pb}^{2+}$ synthetic solution were performed. The removal of Pb ${ }^{2+}$ ion was found to be above $85 \%$.
\end{abstract}

Keywords: retorted shale, adsorption, clays.

\section{INTRODUÇÃO}

O termo xisto, ainda que geologicamente impróprio, é usado generalizadamente para designar as rochas oleígenas no Brasil, ou seja, rochas sedimentares que apresentam um conteúdo apreciável de hidrocarbonetos disseminados em seu meio mineral [1-3]. O termo mais exato para esse tipo de rocha seria "folhelhos", que são rochas resultantes da decomposição de materiais minerais e orgânicos no fundo de grandes lagos ou mares interiores. Os agentes químicos e microorganismos transformam, ao longo de milhões de anos, a matéria orgânica presente nessas rochas em um complexo orgânico de composição indefinida, denominado querogênio (gerador de cera), que, quando convenientemente aquecido, produz um óleo semelhante ao petróleo [4].
O volume de óleo contido no xisto compreende cerca de $7 \%$ do volume da rocha. Esse óleo não é facilmente separado e extraído pelos solventes comuns, os métodos mais utilizados para separá-lo são retortagem, combustão ou liquefação [5]. Os recursos de xisto existente são extremamente abundantes, estima-se que a quantidade de óleo, como reserva potencial, é muitas vezes superior à convencional obtida em poços de petróleo [6].

Atualmente, apenas quatro países no mundo (Brasil, Austrália, China e Estônia) possuem em atividade unidades que fazem o aproveitamento comercial dos recursos do xisto para obtenção de óleo e produção de energia através de termoelétricas. Dentre esses países, o Brasil se destaca como detentor da tecnologia mais avançada. A Unidade de Negócios da Industrialização do Xisto Brasileira (UN-SIX) 
pertence à Petrobrás e está localizada em São Mateus do Sul (PR). Esta unidade está sob a maior reserva brasileira de xisto, a Formação Irati, da qual são extraídas diariamente 7.800 toneladas de xisto [7], e em conseqüência há geração de um rejeito sólido (xisto retortado) que representa 80 a 90\% da matéria prima de alimentação do processo.

Dentro deste contexto o presente trabalho tem como objetivo caracterizar o xisto retortado (XR), e avaliar a possibilidade de utilização desse material como adsorvente para a remoção de chumbo em meio aquoso. Visto que o emprego de resíduos industriais no tratamento de efluentes líquidos, principalmente como materiais adsorventes alternativos, é muitas vezes vantajoso, pois além de remover os contaminantes de efluentes, reduz o impacto ambiental causado pela disposição do próprio resíduo.

\section{MATERIAIS E MÉTODOS}

As amostras de XR de granulometria menor que 200 mesh $(75 \mu \mathrm{m})$ foram provenientes da Unidade de Negócio da Industrialização do Xisto (UN-SIX), localizada em São Mateus do Sul-PR, A análise química das amostras de XR foi realizada empregando o método clássico/instrumental [8-9]. Os referidos métodos foram empregados com o objetivo de comparar os teores dos constituintes químicos das amostras aqui utilizadas com os teores das amostras encontrados em outros trabalhos, uma vez que estes métodos são bastante utilizados na literatura Os espectros na região do infravermelho foram registrados no intervalo espectral de 4000 a $400 \mathrm{~cm}^{-1}$ em um espectrofotômetro Bomen modelo MB 104. As amostras foram diluídas em $\mathrm{KBr}$ e preparadas sob forma de pastilhas. Os difratogramas de raios $\mathrm{X}$ foram obtidos pelo método do pó utilizando radiação $\mathrm{Cu}-\mathrm{k}_{\alpha} \mathrm{e}$ velocidade de varredura de $2 \% \mathrm{~min}$. O equipamento utilizado foi um difratômetro de raios X Rigaku Miniflex. As curvas termogravimétricas foram registradas no intervalo entre 30 e $900{ }^{\circ} \mathrm{C}$, razão de aquecimento de $5^{\circ} \mathrm{C} \cdot \mathrm{min}^{-1} \mathrm{e}$ em atmosfera de ar. O equipamento utilizado foi uma termobalança Perkin Elmer, modelo TGA7. A morfologia do XR foi observada através de micrografias obtidas em um microscópio eletrônico de varredura modelo ESEM-XL30 Philips. Análise por EDS (espectroscopia por dispersão de energia de raios X), também foi realizada para determinação da composição química pontual da amostra. Medidas de área específica foram obtidas pelo método BET em um sistema Nova 2000. A análise granulométrica da fração do XR foi realizada em um granulômetro a laser Cilas 1064.

\section{Ensaios de adsorção}

Os ensaios de adsorção pelo método banho finito (batch), estudando o efeito do $\mathrm{pH}$ e o efeito da quantidade de adsorvente sobre o percentual de adsorção foram conduzidos pelo contato de $1,0 \mathrm{~g}$ de XR com $100 \mathrm{~mL}$ de solução sintética de nitrato de $\mathrm{Pb}^{2+}$ de concentrações conhecidas. A mistura foi agitada sob velocidade de $260 \mathrm{rpm}$ por um determinado intervalo de tempo e temperatura. O efeito do $\mathrm{pH}$ sobre o fenômeno da adsorção foi estudado pela adição de $\mathrm{HCl}$ ou $\mathrm{NaOH}(1,0 \mathrm{M})$ nas soluções. Ao final de um intervalo de tempo pré-determinado, o adsorvente foi removido por filtração e a concentração dos metais no sobrenadante foi determinada por espectroscopia de absorção atômica. A capacidade de adsorção foi estudada ao nível do pH ótimo e tempo de equilíbrio de até $7 \mathrm{~h}$.

\section{RESULTADOS E DISCUSSÃO}

\section{Caracterização do xisto retortado}

Os resultados de algumas propriedades físicas do XR são apresentados na Tabela I. A área superficial encontrada do XR $\left(65 \mathrm{~m}^{2} \cdot \mathrm{g}^{-1}\right)$, é relativamente baixa quando comparada a alguns aluminossilicatos utilizados como adsorventes para remoção de metais pesados, como por exemplo montmorilonita $\left(150-180 \mathrm{~m}^{2} \cdot \mathrm{g}^{-1}\right)$ e zeólita 300-800 $\left(\mathrm{m}^{2} \cdot \mathrm{g}^{-1}\right)$; e relativamente alta em relação a outros adsorventes como siderita $\left(2,67 \mathrm{~m}^{2} \cdot \mathrm{g}^{-1}\right)$ [10], diatomita $\left(3,3 \mathrm{~m}^{2} \cdot \mathrm{g}^{-1}\right)$ [11] e dolomita $\left(0,14 \mathrm{~m}^{2} \cdot \mathrm{g}^{-1}\right)$ [12]. O XR apresenta valor de área superficial na faixa dos valores encontrados na ilita $\left(50-100 \mathrm{~m}^{2} \cdot \mathrm{g}^{-1}\right)$ [13], argilomineral predominante nos xistos piro e betuminosos.

Tabela I - Propriedades físicas do xisto retortado. [Table I- Physical properties of the retorted shale.]

\begin{tabular}{cc}
\hline Propriedades & Valores \\
\hline Densidade aparente $\left(\mathrm{g} / \mathrm{cm}^{3}\right)$ & 0,972 \\
Densidade real $\left(\mathrm{g} / \mathrm{cm}^{3}\right)$ & 1,139 \\
Área superficial específica $\left(\mathrm{m}^{2} / \mathrm{g}\right)$ & 65,08 \\
Volume Total de Poro $\left(\mathrm{cm}^{3} / \mathrm{g}\right)$ & 0,058 \\
Diâmetro médio do Poro $(\AA)$ & 35,92 \\
Diâmetro médio de partícula $(\mu \mathrm{m})$ & 17,56 \\
Distribuição do diâmetro de partícula (\%) & \\
$1,5 \mu \mathrm{m}$ & $10,00^{*}$ \\
$13,25 \mu \mathrm{m}$ & $50,00^{*}$ \\
$40,91 \mu \mathrm{m}$ & $90,00^{*}$ \\
\hline
\end{tabular}

* Valores acumulativos em percentual

A Tabela II apresenta os resultados da análise química do XR pelo método clássico/instrumental das amostras utilizadas neste trabalho e em um conjunto de análises químicas encontradas na literatura referentes a amostras provenientes da UN-SIX. Conforme é observado, a composição química do XR é formada na sua maioria por óxidos ácidos, básicos e anfóteros, os quais garantem na superfície dos grãos a presença de grupos ativos com habilidade para reter metais pesados. Além disso, o XR apresenta aluminossilicatos (argilominerais), como principais constituintes. Estes minerias, além dos característicos sítios de troca iônica, 
possuem os grupos superficiais aluminol ( $\equiv \mathrm{Al}-\mathrm{OH})$ e silanol $(\equiv \mathrm{Si}-\mathrm{OH})$. Estes grupos desprotonados ( $\equiv \mathrm{Si}^{-} \mathrm{O}^{-}$e $\left.\equiv \mathrm{Al}-\mathrm{O}^{-}\right)$ se ligam a metais pesados na forma de estáveis complexos superficiais [14].

Tabela II - Análise química das amostras de xisto retortado pelo método clássico/instrumental.

[Table II - Chemical analysis of the samples of retorted shale for the classic and instrumental method.]

\begin{tabular}{|c|c|c|c|c|c|}
\hline \multirow[t]{2}{*}{ Componente } & \multicolumn{5}{|c|}{ Composição (\%) } \\
\hline & 1 & 2 & 3 & 4 & $\begin{array}{c}\text { Este } \\
\text { trabalho }\end{array}$ \\
\hline Perda ao fogo & 19,16 & 14,4 & 14,7 & 15,9 & 20,10 \\
\hline $\mathrm{SiO}_{2}$ & 50,8 & 55,6 & 57,4 & 56,09 & 51,94 \\
\hline $\mathrm{Al}_{2} \mathrm{O}_{3}$ & 12,6 & 11,4 & 12,1 & 13,01 & 16,9 \\
\hline $\mathrm{Fe}_{2} \mathrm{O}_{3}$ & 6,49 & 8,60 & 8,30 & 8,50 & 6,05 \\
\hline $\mathrm{TiO}_{2}$ & 0,56 & 0,60 & 0,60 & 0,35 & 0,38 \\
\hline $\mathrm{MgO}$ & 1,92 & 1,80 & 1,60 & 1,55 & 1,72 \\
\hline $\mathrm{MnO}$ & - & - & 0,07 & - & - \\
\hline $\mathrm{CaO}$ & 1,42 & 3,50 & 1,50 & 1,50 & 0,08 \\
\hline $\mathrm{K}_{2} \mathrm{O}$ & 2,22 & 2,80 & 2,00 & 1,95 & 1,97 \\
\hline $\mathrm{Na}_{2} \mathrm{O}$ & 1,12 & 1,60 & 1,50 & 1,23 & 1,73 \\
\hline Total & 100,12 & 100,3 & 100,2 & 100,08 & 100,87 \\
\hline Carbono total & 6,98 & 6,70 & & & 6,00 \\
\hline
\end{tabular}

Como informação adicional à análise química, difratogramas das amostras de xisto cru (original) e retortado, Fig. 1, foram obtidos paraidentificação dos principais minerais presentes na amostra. O difratograma da amostra do xisto cru (XC) foi obtido com objetivo de observarmos prováveis alterações na amostra decorrentes do processo de retortagem. Comparando os difratogramas mencionados, observa-se que não ocorrem mudanças qualitativas significantes na fração inorgânica após a retortagem do xisto, visto que foram identificados basicamente os mesmos minerais.

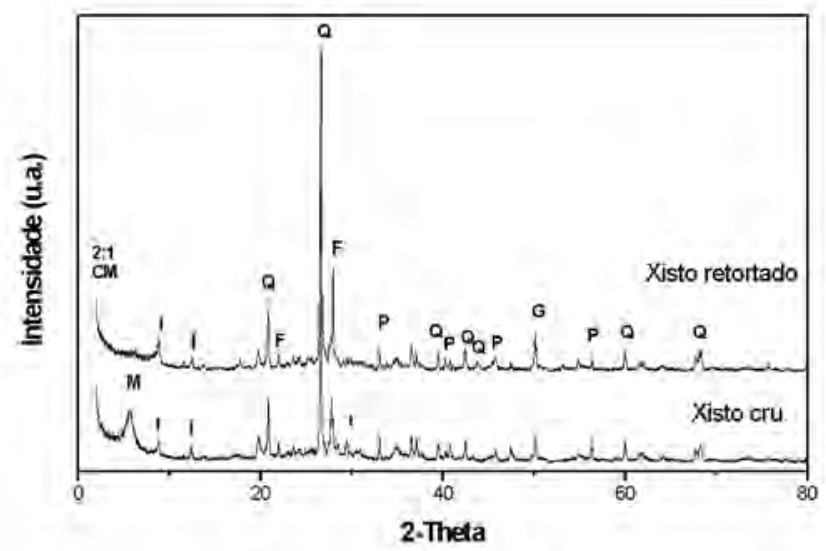

Figura 1: Difratogramas de raios X do XC e XR.

[Figure 1: X ray diffraction patterns of the $R S$ and raw shale.]
Nos referidos difratogramas foram identificadas reflexões correspondentes aos seguintes minerais: quartzo (Q), pirita $(\mathrm{P})$, feldspato plagioclásio $(\mathrm{F})$, gipsita $(\mathrm{G})$, argilominerais de camada mista (2:1 CM) como Ilita (I), montmorilonita (M). Verifica-se que os picos referentes ao quartzo 20,93 e 26,7 $\theta$ (4,24 e 3,34 $\AA$ ) são mais intensos comparados com as outras reflexões, confirmando a quantidade considerável de sílica nas amostras de xisto. Esses resultados são corroborados por Fonseca e cols. [15] que através da caracterização química e mineralógica de amostras da UN-SIX, identificaram estruturas tais como encontradas neste trabalho.

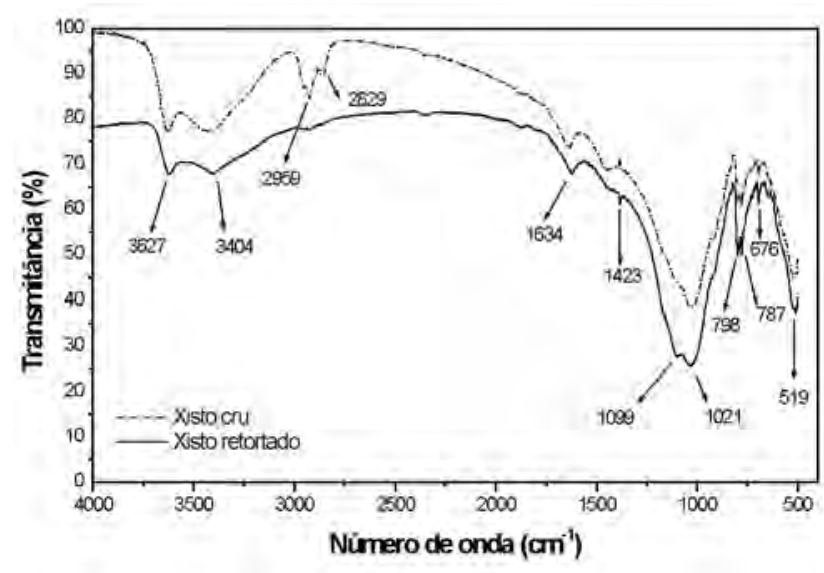

Figura 2: Espectros na região do infravermelho das amostras do XC e XR.

[Figure 2: Infrared spectra of the RS and raw shale samples.]

A existência de grupos funcionais é de fundamental importância para estudos de adsorção, uma vez que muitos deles atuam como sitio ativo para íons metálicos. Os grupos funcionais na superfície das amostras do XR foram identificados através dos espectros de absorção na região do infravermelho (FTIR), Fig. 2. As bandas em 3404 e $3627 \mathrm{~cm}^{-1}$ são atribuídas ao estiramento $\mathrm{O}-\mathrm{H}$ de grupos hidroxílicos e de água adsorvida [16]. Também foram identificadas bandas relativas à matéria orgânica, vCH $\left(2959\right.$ e $\left.25829 \mathrm{~cm}^{-1}\right)$. A presença de argilominerais e quartzo na amostra são evidenciados pelo estiramento da ligação Si-O, em aproximadamente $1021 \mathrm{~cm}^{-1}$, vibrações assimétricas Si-O em $1423 \mathrm{~cm}^{-1}$ e um dublete próximo a $800 \mathrm{~cm}^{-1}$ (798 e $\left.787 \mathrm{~cm}^{-1}\right)$, atribuído à deformação $\delta \mathrm{OH}$ da ligação Si-OH [16, 17]. O pico em 1634 $\mathrm{cm}^{-1}$ pode ser atribuído às vibrações $\mathrm{C}=\mathrm{O}$ dos carboxilatos (vCO), proveniente da matéria orgânica[11-12, 16]. A banda em $519 \mathrm{~cm}^{-1}$ é atribuída ao estiramento vM-O (M = metal) e corresponde aos óxidos presentes nas amostras [12]. Os principais grupos funcionais, que possibilitará a remoção de metais são os grupos silanóis ( $\left.\mathrm{Si}^{-} \mathrm{O}^{-}\right)$, hidroxílicos $(\mathrm{OH})$ e os carboxílico (-COOH) da matéria orgânica [18]. O oxigênio desses grupos é considerado uma forte base de Lewis por causa da presença do par de elétrons livres, podendo formar um complexo de coordenação com entidades químicas elétron-deficiente, com os íons metálicos. 
Curvas termogravimétricas foram obtidas para verificar a estabilidadee a presença de espécies orgânicas presentes no XR. As curvas termogravimétricas das amostras de XC e XR podem ser observadas nas Figs. 3a e 3b, respectivamente. As curvas obtidas nesse trabalho não diferem das curvas encontradas por outros autores que estudaram o comportamento térmico do xisto retortado da Formação Irati [10, 18-19]. Esses autores identificaram perdas correspondentes à queima do carbono residual e da pirita, perda de água estrutural, desidroxilação de argilominerais e decomposição de carbonatos. Basicamente, tem-se até $240{ }^{\circ} \mathrm{C}$ a perda de água relativa à umidade e água intercalada entre as camadas 2:1 e mistas das frações dos argilominerais presentes nas amostras. A partir de $400{ }^{\circ} \mathrm{C}$ ocorrem tanto à queima do rejeito orgânico remanescente do XR como a queima da pirita $\left(\mathrm{FeS}_{2}\right)$; e a partir de $550{ }^{\circ} \mathrm{C}$, ocorre desidroxilação da fração dos argilominerais. A perda de massa total que ocorre nestas amostras aquecidas até aproximadamente $1000^{\circ} \mathrm{C}$ é de 20,03 e 16,63\% para os XC e XR, respectivamente. A perda de massa que ocorre em
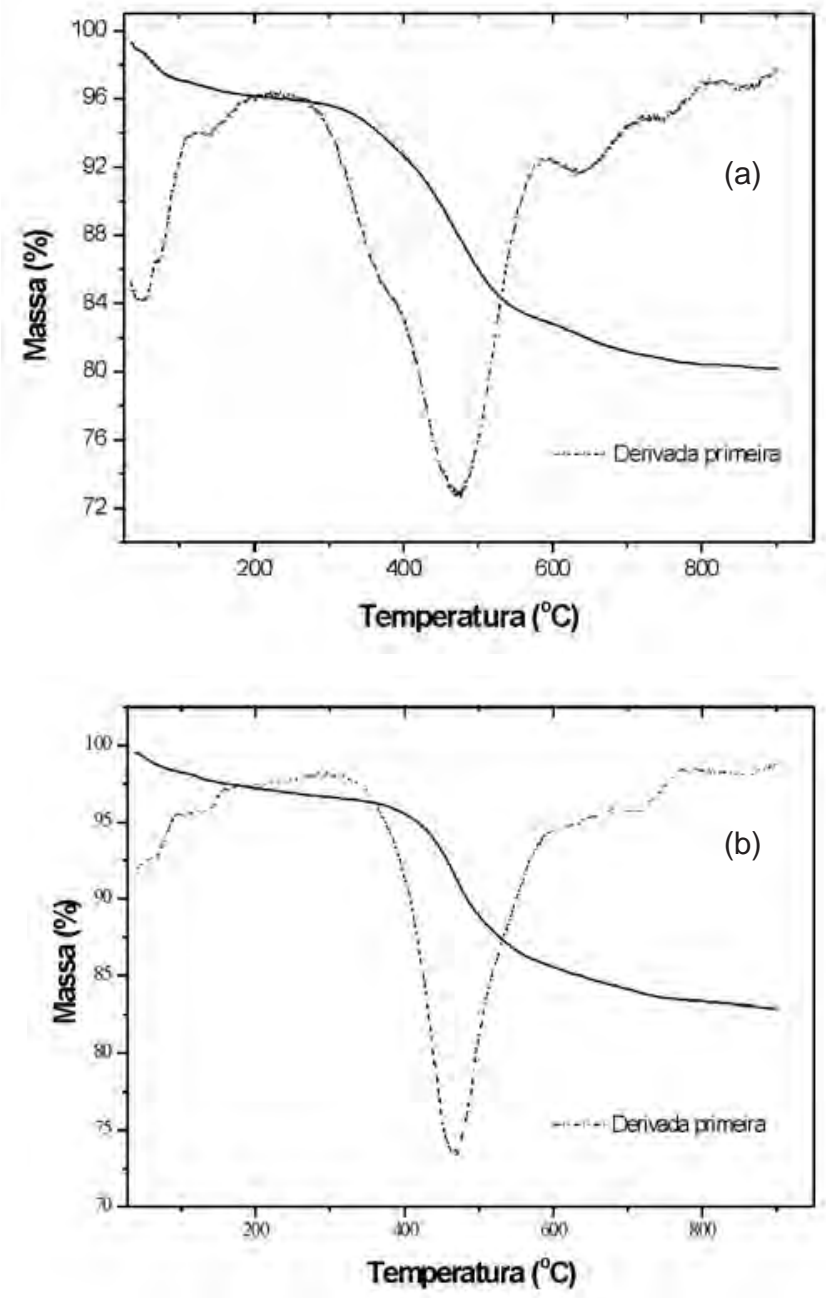

Figura 3: Curvas termogravimétricas das amostras XC (a) e XR (b). [Figure 3: Thermogravimetric curves of the raw shale (a) and RS (b).] aproximadamente $600{ }^{\circ} \mathrm{C}$ na amostra de XR é um indicativo que existe ainda um conteúdo apreciável de matéria orgânica em relação ao XC. Esses resultados foram corroborados pela análise de infravermelho, cujas bandas referentes à matéria orgânica são mais acentuadas no espectro do XC.

A Fig. 4 apresenta micrografias de amostras do XR. Na Fig. 4a, além de aglomerados, são observadas formas cúbicas características de cristais de pirita $\left(\mathrm{FeS}_{2}\right)$. Esta micrografia revela a heterogeneidade do material. Na Fig. 4b pode-se observar o caráter poroso do material e partículas com placas lamelares características dos argilominerais, provavelmente de ilita e sericita, argilominerais predominantes em xistos pirobetuminosos [5]. As regiões porosas são favoráveis ao fenômeno de adsorção, além de ser um indicativo de área superficial considerável.
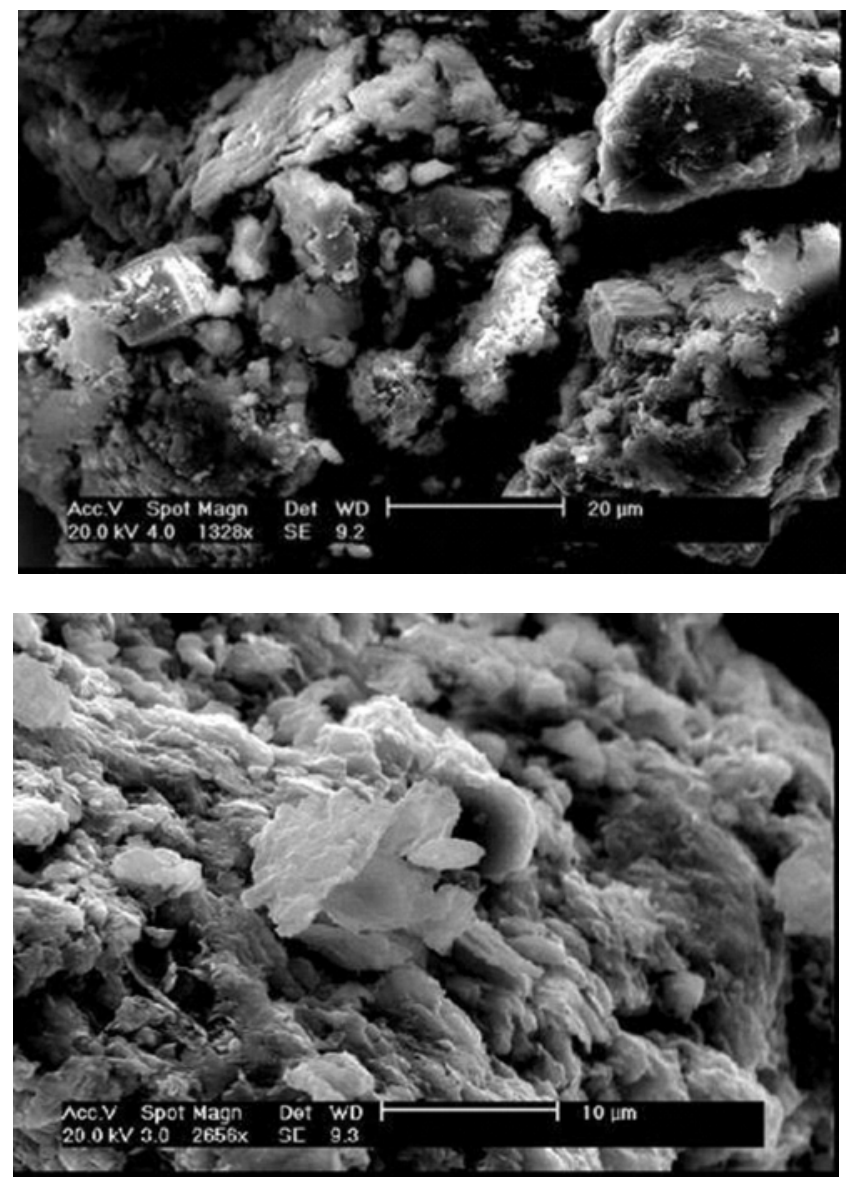

Figura 4: Microscopia eletrônica de varredura do xisto retortado. [Figure 4: Scanning electron microscopy micrographs of the RS.]

Análise por microssonda eletrônica (EDS), Fig. 5, da região apontada com uma seta (Fig. 4a), revela a predominância em silício (28,07\%), alumínio (7,89\%) e oxigênio $(46,3 \%)$, elementos que compõe a estrutura dos aluminossilicatos, como também, enxofre (3,75\%) e ferro (2,64\%), elementos constituintes do mineral pirita. Esta informação corrobora as informações obtidas nos 
difratogramas de raios $\mathrm{X}$, onde foram identificadas reflexões correspondentes a esse mineral.

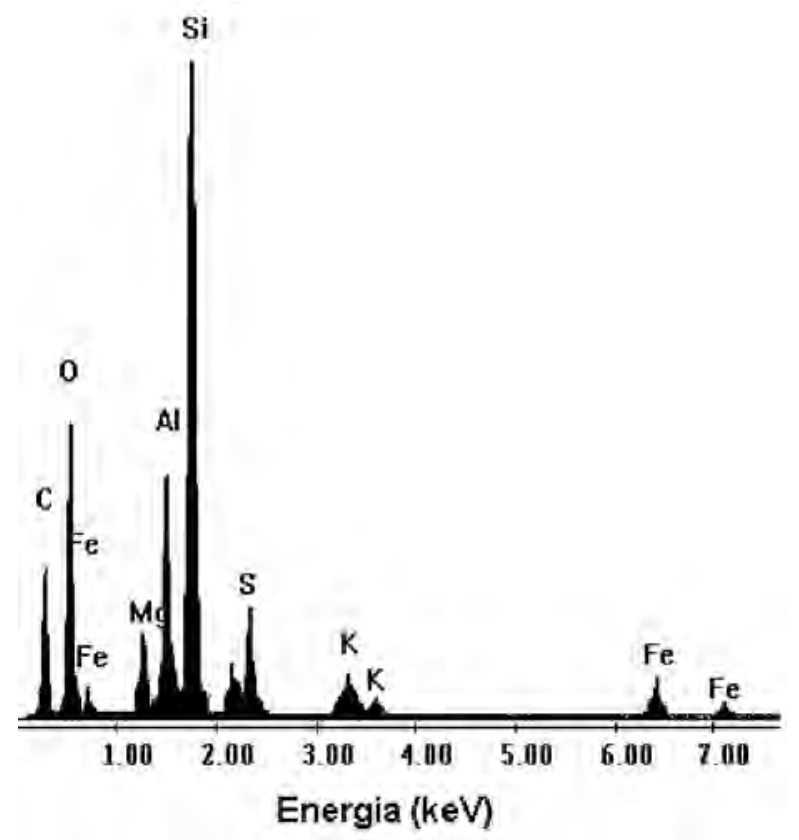

Figura 5: EDS da amostra de XR.

[Figure 5: EDX of the RS.]

\section{Ensaios de adsorção}

A determinação de um $\mathrm{pH}$ ótimo é importante, uma vez que o pH é um dos parâmetros que influenciam no percentual de adsorção [20]. É observado na Fig. 6 que o percentual de adsorção é baixo a baixos valores de $\mathrm{pH}$ e

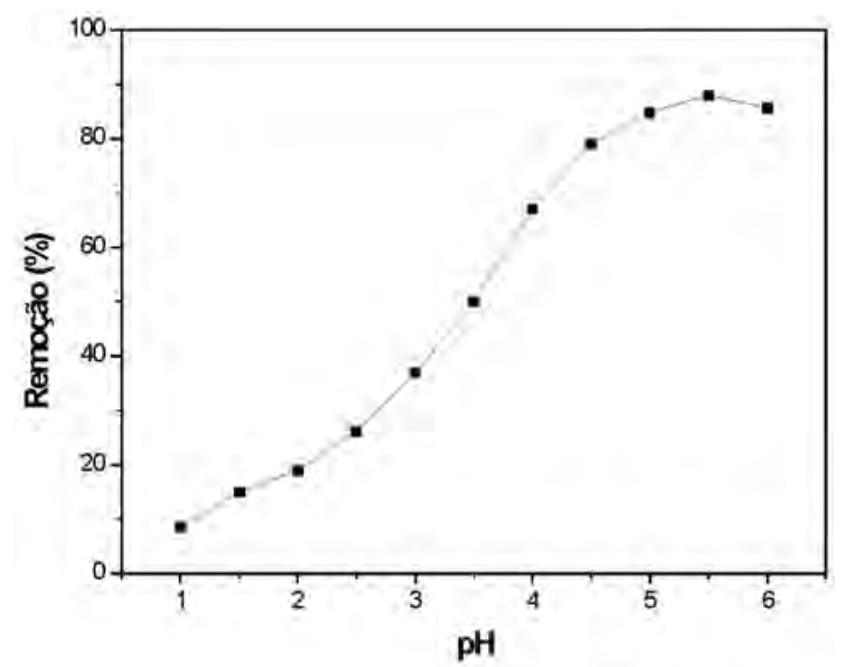

Figura 6: O efeito do pH sobre o percentual de adsorção dos íons $\mathrm{Pb}^{2+}$ em XR.

[Figure 6: Effect of $\mathrm{pH}$ on the $\mathrm{Pb}^{2+}$ adsorption by RS.] aumenta com o aumento do $\mathrm{pH}$ alcançando um máximo no $\mathrm{pH}$ 5. A valores maiores de $\mathrm{pH}$, os íons começam a precipitar na forma de hidróxidos metálicos. Uma das explicações para este comportamento segue que em baixos valores de $\mathrm{pH}$ a superfície tem densidade de carga altamente positiva e sob estas condições a adsorção de metais será dificultada devido à competição com os íons $\mathrm{H}^{+}$. Com o aumento do $\mathrm{pH}$, a densidade de carga negativa da superfície do adsorvente aumenta, resultando numa menor repulsão eletrostática entre a superfície e o íon metálico, como também, um decrescimento na competição entre o próton e o metal pelo mesmo grupo funcional e conseqüentemente aumentando a adsorção.

$\mathrm{O}$ efeito da quantidade de adsorvente sobre o percentual de adsorção de chumbo II está mostrado na Fig. 7. Os dados indicam que a adsorção aumenta com o aumento da quantidade de adsorvente, alcançando um máximo de remoção em 1,4 g de XR por solução de chumbo 200 mg/L.

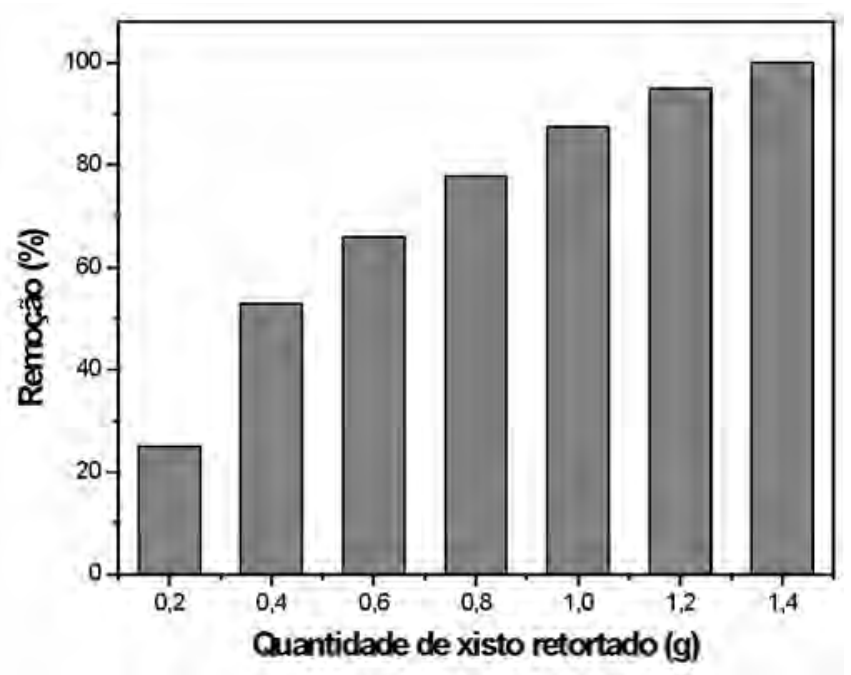

Figura 7:- Efeito da quantidade de adsorvente sobre o processo de adsorção.

[Figure 7: Effect of adsorbentcontent on the process of adsorption process.]

\section{CONCLUSÃO}

$\mathrm{Na}$ caracterização físico-química, verifica-se que a composição do XR garante na superfície dos grãos a presença de grupos ativos provenientes das espécies minerais e dos resíduos orgânicos que atribuem às amostras características de adsorventes. As amostras de XR foram utilizadas nos ensaios de adsorção sem nenhum tratamento prévio. A utilização do material adsorvente desta forma tende a reduzir o seu custo, como também o do processo como um todo, aumentando assim a possibilidade de sua utilização em processos de tratamento de efluentes industriais. Os ensaios de adsorção realizados com soluções sintéticas mostraram 
que o XR apresentou bom desempenho em remover o íon estudado $\left(\mathrm{Pb}^{2+}\right)$, podendo ser efetivamente usado como adsorvente para remoção destes metais em meio aquoso.

\section{AGRADECIMENTOS}

À Agência Nacional do Petróleo (ANP) pelo suporte financeiro para realização deste trabalho, à UNISIX e ao CENPES pelas amostras de xisto fornecidas.

\section{REFERÊNCIAS}

[1] H. S. Pereira, G. C. Vitti, G. H. Korndorfer, Rev. Bras. Ci. Solo 27 (2003) 1.

[2] V. T. Padula, Boletim Tecnológico da Petrobrás. 11 (1968) 407.

[3] M. V. A Fonseca, R. S. V. Nascimento, P. Souza Santos, C. Costa Neto, Boletim Tecnológico da Petrobrás 32, 1-2 (1989) 35.

[4] M. V. A. Fonseca, Estudo da lixiviação ácida do resíduo de retortagem do xisto, Diss. Mestrado, Programa de Engenharia Química, COPPE, Universidade Federal do Rio de Janeiro, RJ (1983).

[5] P. Souza Santos, Ciência e Tecnologia de Argilas, $2^{\text {a Ed., }}$ vol. 3, Ed. Edgard Blücher, S. Paulo (1992).

[6] N. Golubev, Oil Shale 20, 3 (2003) 324.

[7] A. C. A Costa, L. M. S. Mesquita, J. Tornovsky, Minerals Eng. 8 (1996) 811.
[8] P. Souza e Santos, Ciência e Tecnologia de argilas, $2^{\text {a }}$ Ed., Ed. Edgard Blücher, S. Paulo (1989).

[9] H. S. Gomes Jr, Adsorção de óleo em água de produção sobre vermiculita hidrofobizada em banho finito, Tese de Doutorado, PGGCEM, UFRN, Natal, RN (2002).

[10] M. Erdem, A. Ozverdi, Separation and Purification Technology 42 (2005) 259.

[11] M. A. M. Khraisheh, Y. S. Al-Degs, W. A. M. Mcminn, Chem. Eng. J. 99 (2004) 177.

[12] S. Karaca, A. Gürses, M. Fjder, M. Açikyildiz0, J. Colloid and Interface Sci. 277 (2004) 257.

[13] M. R. M. P. Aguiar, A. C. Novaes, A. W. S. Guarino, Quím. Nova 25, 6B (2002) 1145.

[14] H. B. Bradl, J. Colloid and Interface Sci. 277 (2004) 1.

[15] M. C. Fonseca, M. V. A. Fonseca, T. P. Cunha, Cerâmica 30 (1984) 183.

[16] G. Haberhauer, B. Rafferty, F. Strebl, M. H. Gerzabek, Geoderma 83 (1988) 331.

[17] J. Davidovits, Synthetic mineral polymer compound of silicoaluminates family and preparation process, US Patent 4.472.199 (18 Set 1984).

[18] C. Costa Neto, M. C. Fonseca, M. V. A. Fonseca, T. P. Cunha, Cerâmica 27 (1981) 357.

[19] C. Costa Neto, A. L. Scofield, Anais da Acad. Bras. Ci. 49, 3 (1977) 389.

[20] H. A. Elliott, C. P. Huang, Water Research 15, 7 (1981) 849.

(Rec. 20/10/2005, Rev. 27/01/2006, Ac. 06/02/2006) 